\title{
Multisystem Inflammatory Syndrome after SARS-CoV-2 Infection and COVID-19 Vaccination
}

\author{
Mark B. Salzman, Cheng-Wei Huang, Christopher M. O’Brien, Rhina D. Castillo
}

We report 3 patients in California, USA, who experienced multisystem inflammatory syndrome (MIS) after immunization and severe acute respiratory syndrome coronavirus 2 infection. During the same period, 3 adults who were not vaccinated had MIS develop at a time when $\approx 7 \%$ of the adult patient population had received $\geq 1$ vaccine.

M ultisystem inflammatory syndrome (MIS) in children (MIS-C) and adults (MIS-A) are febrile syndromes with elevated inflammatory markers that usually manifest 2-6 weeks after a severe acute respiratory syndrome 2 (SARS-CoV-2) infection (1-3). The Brighton Collaboration Case Definition for MIS$\mathrm{C} / \mathrm{A}$ was recently published to be used in the evaluation of patients after SARS-CoV-2 immunization (3); some scientists are concerned that vaccination against SARS-CoV-2 can trigger MIS-C/A. We report 6 cases of MIS from a large integrated health system in Southern California, USA; 3 of those patients received SARS-CoV-2 vaccination shortly before seeking care for MIS. All 6 patients met the Brighton Collaboration Level 1 of diagnostic certainty for a definitive case and had MIS illness onset between January 15February 15, 2021. The Chief Compliance Officer for the Southern California Permanente Medical Group reviewed this case series and confirmed that it was compliant with the Health Insurance Portability and Accountability Act for publication.

\section{The Study}

Patient 1 was a 20 -year-old Hispanic woman who sought care for 3 days of a diffuse body rash, tac-

Author affiliations: Kaiser Permanente West Los Angeles Medical Center, Los Angeles, California, USA (M.B. Salzman); Kaiser Permanente Los Angeles Medical Center, Los Angeles (C.-W. Huang); Kaiser Permanente Zion Medical Center, San Diego, California, USA (C.M. O'Brien); Kaiser Permanente Tustin Ranch Medical Offices, Tustin, California, USA (R.D. Castillo)

DOI: https://doi.org/10.3201/eid2707.210594 tile fever, sore throat, mild neck discomfort, and fatigue. There was no cough, congestion, headache, or abdominal pain. She had vomiting and diarrhea, which had subsided 8 days before admission. She received her first dose of SARS-CoV-2 vaccine 15 days before admission. She had no known coronavirus disease (COVID-19) exposure but was SARSCoV-2 PCR and nucleocapsid IgG positive. She was hypotensive at arrival to the emergency department, requiring inotropic support. She had elevated troponin and brain natriuretic peptide (BNP) with a left ventricular ejection fraction initially mildly reduced at $45 \%$ but $30 \%-35 \%$ the following day. She responded well to therapy with intravenous immunoglobulin (IVIG) and methylprednisolone (Table 1).

Patient 2 was a 40-year-old Hispanic man who sought care after 6 days of episodic fevers up to $101.7^{\circ} \mathrm{F}$. Associated symptoms included dyspnea on exertion, headache, neck pain, lethargy, abdominal pain, and diarrhea. No chest pain was present. He had a history of SARS-CoV-2 vaccination and laboratory-confirmed mild to moderate COVID-19, both within 48 days before seeking care (Figure). His exam was notable for sweats, diffuse abdominal pain on palpation, tachycardia, and tachypnea. Patient 2 fulfilled Brighton Level 1 criteria for MIS-A with documented fevers, gastrointestinal and neurologic symptoms, elevated inflammatory and cardiac markers, and electrocardiogram changes that were concerning for myocarditis (3). He responded well to treatment with dexamethasone (Table 1).

Patient 3 was an 18-year-old Asian American man who sought care at the emergency department with a history of 3 days of fever as high as $104^{\circ} \mathrm{F}$ with headache, vomiting, diarrhea, and abdominal cramping (Figure). He denied any upper respiratory symptoms. He had a history of a laboratoryconfirmed COVID-19 infection 6 weeks before the onset of symptoms and received the first dose of 
the SARS-CoV-2 vaccine 18 days before the onset of symptoms. In the emergency department, he was found to be hyponatremic and hypotensive (Table 1). His examination was notable for tachycardia and abdominal tenderness. He had elevated inflammatory markers, thrombocytopenia, and lymphopenia. Echocardiogram revealed mild to moderate reduced systolic function with an ejection fraction

Table 1. Demographic, laboratory, and clinical characteristics of 3 patients who had multisystem inflammatory syndrome after SARSCoV-2 immunization, Southern California, USA

\begin{tabular}{lc}
\hline Characteristic & Patient 1 \\
\hline Age, y/sex & 20 y/F \\
\hline Race/ethnicity & Hispanic/Latina \\
\hline Underlying conditions & Asthma \\
\hline Symptoms & $\begin{array}{c}\text { Fever and rash for } 3 \text { d, diarrhea, } \\
\text { vomiting, cardiogenic shock, } \\
\text { acute renal failure }\end{array}$ \\
\hline Initial vital signs & Pulse: 130 beats $/$ min, BP $73 / 56$ \\
& mm Hg, RR 20 breaths $/$ min, \\
& temp $99.4^{\circ} \mathrm{F}$, repeat temp 101.4, \\
& O2 sats $99 \%$ on RA; BMI: 27.85 \\
\hline Treatment & Vasopressors $\times 3$ d, IVIG $100 \mathrm{~g}$, \\
& methylprednisolone $1 \mathrm{~g} / \mathrm{d}$ for 3 \\
& $\mathrm{~d}$, heparin, broad spectrum \\
& antibiotics, remdesivir \\
\hline Imaging & TTE: normal LV, mildly reduced \\
& EF 45\% which decreased to \\
& $30 \%-35 \%$ the next day; chest \\
& radiograph: subtle bibasilar \\
& ground glass opacities
\end{tabular}

Patient 2
40 y/M
Hispanic/Latino
Depression, hyperlipidemia
6 d of fevers, malaise,
diarrhea, neck pain,
headache, lethargy
Pulse 102 beats/min, BP
$136 / 88$ mm Hg, RR 20
breaths/min, temp $99.2^{\circ} \mathrm{F}, \mathrm{O} 2$
sats $97 \%$ on RA; BMI: 28.89
Dexamethasone 6 mg/d for
10 d, ceftriaxone,
azithromycin, enoxaparin

EKG: ST depression and T
wave inversion in inferior
leads; TTE: normal LV; EF:
$50 \%-55 \%$; CT angiogram: no
pulmonary embolism, minimal
ground glass opacities




\section{Patient 1}

Vaccine \#1

Day -12
MIS admission

Day 3

$\bullet$
MIS symptom onset
Day 0

Patient 2

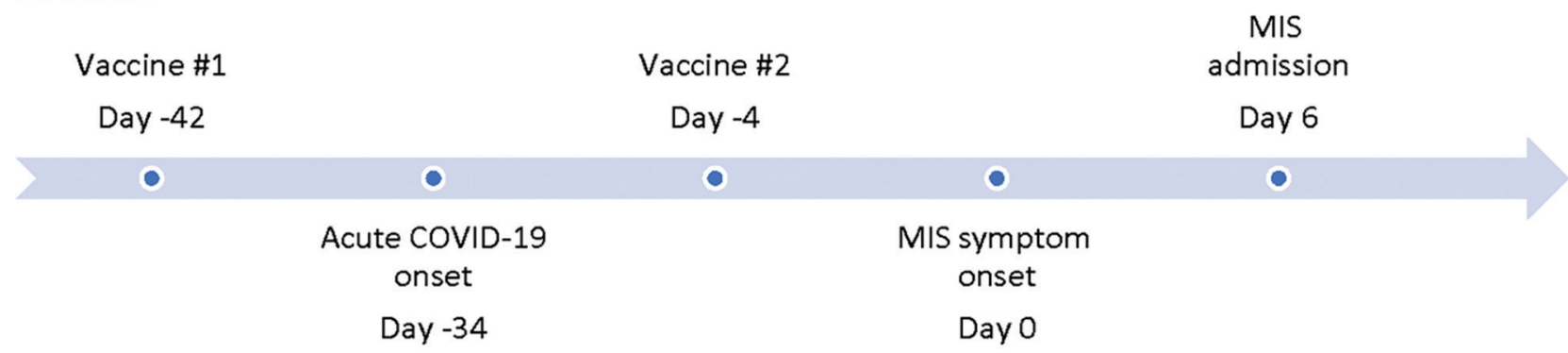

Patient 3

Acute COVID-19

onset

Day -43
MIS symptom

onset

Day 0

$\begin{array}{cc}\text { Vaccine \#1 } & \bullet \\ \text { Day }-19 & \text { MIS admission } \\ \text { Day } 3\end{array}$

Figure. Timeline displaying intervals between coronavirus (COVID-19) vaccine, acute COVID-19 symptom onset, and MIS symptom onset in patients in California, USA. MIS, multisystem inflammatory syndrome.

of $40 \%-45 \%$. He responded well to therapy with methylprednisolone, IVIG, and anakinra.

Patient 4 was a 62-year-old Asian American man who sought care at the emergency department for fever lasting 5 days. For 6 days he had had nausea and vomiting, which developed 23 days after a laboratory-confirmed mild to moderate acute COVID-19 illness that subsided after 1 week. He also had 4 days of bilateral hearing loss. He was hypotensive, requiring inotropic support. He had thrombocytopenia, elevated inflammatory markers, and elevated troponin with diffuse ST elevations on electrocardiogram (Table 2). He responded well to treatment with methylprednisolone, including improvement in his hearing loss.

Patient 5 was a 29-year-old Hispanic woman who experienced fever, chills, headache, and nausea 28 days after a laboratory-confirmed acute COVID-19 illness. She sought care at the emergency department with hypotension requiring inotropic support. Clinicians diagnosed MIS-A on the basis of conjunctivitis, evidence of colitis on abdominal imaging, elevated inflammatory markers, lymphopenia, and elevated
BNP. She responded well to treatment with methylprednisolone and IVIG (Table 2).

Patient 6 was a 23-year old Hispanic man who experienced fever and abdominal pain 38 days after a laboratory-confirmed mild to moderate acute COVID-19 illness. He was hypotensive, requiring inotropic support. He had mesenteric adenitis on abdominal imaging. He had elevated inflammatory markers, neutrophilia, lymphopenia, and a left ventricular ejection fracture of $20 \%$ on echocardiogram. He was treated with IVIG and methylprednisolone (Table 2). He died 12 days after admission.

\section{Conclusions}

At the time of our study, our medical group was only vaccinating healthcare workers and patients $\geq 75$ years of age. The 3 patients that were immunized qualified for early vaccination because they either worked or volunteered in a healthcare setting. These cases occurred $\approx 1$ month after the peak surge of COVID-19 cases in Southern California. At the time these patients sought care, only $\approx 7 \%$ of the adult ( $\geq 18$ years of age) population who were 
Table 2. Demographic, laboratory, and clinical characteristics of patients who had multisystem inflammatory syndrome without SARSCoV-2 immunization, California, USA

\begin{tabular}{|c|c|c|c|}
\hline Characteristic & Patient 4 & Patient 5 & Patient 6 \\
\hline Age/sex & $62 \mathrm{y} / \mathrm{M}$ & $29 \mathrm{y} / \mathrm{F}$ & $23 \mathrm{y} / \mathrm{M}$ \\
\hline Race/ethnicity & Asian & Hispanic/Latina & Hispanic/Latino \\
\hline Underlying conditions & $\begin{array}{l}\text { Hyperlipidemia, gout, atrial } \\
\text { fibrillation }\end{array}$ & Obesity & Asthma, obesity \\
\hline Signs and symptoms & $\begin{array}{l}6 \mathrm{~d} \text { of fever, vomiting, abdominal } \\
\text { pain, } 4 \mathrm{~d} \text { of hearing loss; shock, } \\
\text { acute renal failure }\end{array}$ & $\begin{array}{l}4 \mathrm{~d} \text { of fever, headaches, } \\
\text { vomiting, abdominal pain; } \\
\text { conjunctivitis, shock, } \\
\text { acute kidney injury }\end{array}$ & $\begin{array}{l}4 \mathrm{~d} \text { of fever, abdominal pain, } \\
\text { diarrhea, cough, SOB; shock }\end{array}$ \\
\hline Initial vital signs & $\begin{array}{c}\text { Pulse } 121 \text { beats/min, BP } 112 / 63 \\
\text { mm Hg, RR } 20 \text { breaths/min, temp } \\
101.6^{\circ} \mathrm{F}, \mathrm{O} 2 \text { sats } 98 \% \text {; within } 1 \mathrm{~h} \\
\text { in ER: BP } 70 / 56 \mathrm{~mm} \text { Hg, pulse } \\
112 \text { beats/min, RR } 28 \text { breaths/ } \\
\text { min, O2 sat } 97 \% \text {; BMI: } 28.1\end{array}$ & $\begin{array}{c}\text { Pulse } 140 \text { beats/min, BP } \\
102 / 71 \mathrm{~mm} \mathrm{Hg}(61 / 48 \mathrm{~mm} \mathrm{Hg} \\
\text { after } 5 \mathrm{~h} \text { of being in } \mathrm{ER}), \mathrm{RR} \\
20 \text {, temp } 105.2^{\circ} \mathrm{F}, \mathrm{O} 2 \\
\text { sats } 99 \% \text {; BMl: } 31.63\end{array}$ & $\begin{array}{c}\text { Pulse } 125 \text { beats/min, BP } \\
87 / 27 \mathrm{~mm} \mathrm{Hg} \text {, temp } 98.2^{\circ} \mathrm{F} \text {, } \\
\text { O2 sats } 98 \% \text { on } \mathrm{RA} ; \\
\text { BMl: } 40.3\end{array}$ \\
\hline Treatment & $\begin{array}{c}\text { Vasopressors, } \\
\text { methylprednisolone } 125 \text { mg every } \\
6 \mathrm{~h} \text {, broad spectrum antibiotics, } \\
\text { enoxaparin }\end{array}$ & $\begin{array}{c}\text { Vasopressors, } \\
\text { methylprednisolone } 30 \mathrm{mg} \\
\text { every } 12 \mathrm{~h}, \text { IVIG } 100 \mathrm{~g}, \\
\text { heparin, ceftriaxone, } \\
\text { ciprofloxacin }\end{array}$ & $\begin{array}{l}\text { Vasopressors, IVIG } 2 \mathrm{~g} / \mathrm{kg} \text {, } \\
\text { methylprednisolone } 1 \mathrm{~g} \text { daily } \\
\text { for } 3 \mathrm{~d} \text {, broad spectrum } \\
\text { antibiotics }\end{array}$ \\
\hline Imaging & $\begin{array}{l}\text { EKG: diffuse ST elevation; TTE: } \\
\text { mild concentric LVH, mild LV } \\
\text { systolic dysfunction, EF 50\%; CT } \\
\text { angiogram: no evidence of } \\
\text { embolus; increased interstitial } \\
\text { markings and hazy ground glass } \\
\text { changes, small bilateral pleural } \\
\text { effusions; } 6 \text { mm pericardiac } \\
\text { effusion; ultrasound: } \\
\text { right popliteal DVT }\end{array}$ & $\begin{array}{l}\text { TTE: LVEF } 50 \%-55 \% \text {, mild } \\
\text { TR regurgitation, abdominal } \\
\text { CT with colitis and enlarged } \\
\text { lymph nodes }\end{array}$ & $\begin{array}{l}\text { EKG: sinus tachycardia, no } \\
\text { ST changes; TTE: LVEF } \\
\text { 20\%, global hypokinesis, } \\
\text { abdominal CT with } \\
\text { mesenteric adenitis }\end{array}$ \\
\hline Length of hospital stay & $7 \mathrm{~d}$ & $10 \mathrm{~d}$ & $12 \mathrm{~d}$; deceased \\
\hline First vaccine & NA & NA & NA \\
\hline Second vaccine & NA & NA & NA \\
\hline Previously known COVID-19 & 23 days before symptom onset & $28 \mathrm{~d}$ before symptom onset & $38 \mathrm{~d}$ before symptom onset \\
\hline \multicolumn{4}{|l|}{ Initial lab results (reference ranges) } \\
\hline $\begin{array}{l}\text { Serum leukocytes, } \times 1,000 / \mathrm{mcL} \\
(4.5-14.5)\end{array}$ & 18.4 & 10.2 & 6.8 \\
\hline $\begin{array}{l}\text { Lymphocytes absolute, } \\
\times 1,000 / \mathrm{mcL}(1.5-6.8)\end{array}$ & 0.00 & 0.35 & 0.52 \\
\hline $\begin{array}{l}\text { Neutrophils absolute, } \\
\times 1,000 / \mathrm{mcL}(1.5-8.00)\end{array}$ & 17.66 & 9.66 & 14.35 \\
\hline $\begin{array}{l}\text { Platelets, } \times 1,000 / \mathrm{mcL} \\
(130-400)\end{array}$ & 102 & 170 & 185 \\
\hline Creatinine, $\mathrm{mg} / \mathrm{dL}(\leq 1.00)$ & 2.24 & 0.78 & 2.49 \\
\hline C-reactive protein, mg/L $(<7.4)$ & 351.7 & 364.9 & 246.3 \\
\hline D-dimer, $\mu \mathrm{g}$ FEU/mL $(\leq 0.49)$ & 7.21 & 5.79 & $>4$ \\
\hline Ferritin, ng/mL (17-168) & 5,032 & 606 & $\begin{array}{c}1,273 \text { at admission, }>18,000 \\
\text { at its peak } 2 \text { days later }\end{array}$ \\
\hline Fibrinogen, mg/dL (218-441) & N/A & N/A & 454 \\
\hline Troponin, ng/mL (<0.03) & 0.85 & 0.06 & $<0.02$ \\
\hline BNP, $\mathrm{pg} / \mathrm{mL}(\leq 99)$ & 931 & 331 & 228 \\
\hline LDH, U/L (<279) & 267 & $N / A$ & 224 \\
\hline AST, U/L $(\leq 34)$ & 38 & N/A & 42 \\
\hline $\mathrm{ALT}, \mathrm{U} / \mathrm{L}(\overline{<} 63)$ & 40 & 558 & 88 \\
\hline Procalcitonin, ng/mL (0.0-0.1) & Not done & 8.15 & 29.37 \\
\hline $\begin{array}{l}\text { SARS-COV-2 nucleocapsid } \\
\text { IgG qualitative }\end{array}$ & Not done & Positive & Not done \\
\hline SARS-COV-2 PCR & Positive & Negative & Positive \\
\hline Blood culture & Negative $\times 2$ & Negative $\times 4$ & Negative $\times 9$ \\
\hline Urine culture & Negative (after antibiotics) & Negative (after antibiotics) & Negative (after antibiotics) \\
\hline Bacterial GI PCR panel & Not done & Negative & Not done \\
\hline
\end{tabular}


members of the Kaiser Permanente patient group $(\approx 3,776,000$ members $)$ had received $\geq 1$ SARS-CoV-2 vaccine, whereas 3 of the 6 patients in this study who had MIS were vaccinated. These 6 patients were hospitalized at 5 of the 15 Kaiser Permanente medical centers across Southern California. We believe the temporal association after SARS-CoV-2 immunization is worth noting, given the theoretical concern of MIS-C/A after vaccination (3). We did not identify any patients with MIS after vaccination who did not have recent SARS-CoV-2 infection. It is possible that other case-patients in our member population were hospitalized outside of our 15 medical centers and thus were not captured for this case series.

Overall, MIS is rare in adults. In comparison we treated $>50$ children with MIS-C during January 2021-February 2021 and >100 since May 2020 among a pediatric population of 960,000 .

The Centers for Disease Control and Prevention (CDC) allows for vaccination after a SARS-CoV-2 infection after recovery from the acute illness and after the isolation period, with no recommended minimal interval between infection and vaccination (4). Most cases of MIS-C/ A occur 2-6 weeks after an exposure or infection (1-3), although we have seen several children brought for care as late as 8-10 weeks after a confirmed infection or exposure. We need to continue to monitor for MIS-C/A after SARS-CoV-2 infection and immunization as more of the population are vaccinated, especially as vaccines are administered to children who are at higher risk for MIS. CDC and the US Food and Drug Administration co-manage VAERS (the Vaccine Adverse Event Reporting System), which is being used to monitor for adverse events after COVID-19 vaccines. MIS-C/A is listed as a postvaccination adverse event of special interest (5) and should be reported to VAERS (6).

\section{About the Author}

Dr. Salzman is a pediatric infectious diseases physician and assistant chief of the Department of Pediatrics at Kaiser Permanente West Los Angeles Medical Center, Los Angeles, California. He is also the regional lead physician in pediatric infectious diseases for the Southern California Permanente Medical Group.

\section{References}

1. Morris SB, Schwartz NG, Patel P, Abbo L, Beauchamps L, Balan S, et al. Case series of multisystem inflammatory syndrome in adults associated with SARS-CoV-2 infectionUnited Kingdom and United States, March-August 2020. MMWR Morb Mortal Wkly Rep. 2020;69:1450-6. https:/ / doi.org/10.15585/mmwr.mm6940e1

2. Godfred-Cato S, Bryant B, Leung J, Oster ME, Conklin L, Abrams J, et al.; California MIS-C Response Team. COVID-19-associated multisystem inflammatory syndrome in children - United States, March-July 2020. MMWR Morb Mortal Wkly Rep. 2020;69:1074-80. https:/ / doi.org/ 10.15585/mmwr.mm6932e2

3. Vogel TP, Top KA, Karatzios C, Hilmers DC, Tapia LI, Moceri $\mathrm{P}$, et al. Multisystem inflammatory syndrome in children and adults (MIS-C/A): case definition \& guidelines for data collection, analysis, and presentation of immunization safety data. Vaccine. 2021 Feb 25 [Epub ahead of print]. https://doi.org/10.1016/jvaccine.2021.01.054

4. US Centers for Disease Control and Prevention. Interim clinical considerations for use of COVID-19 vaccines currently authorized in the United States. April 27, 2021 [cited 2021 May 12]. https://www.cdc.gov/vaccines/ covid-19/info-by-product/clinical-considerations.html

5. US Centers for Disease Control and Prevention. Vaccine Adverse Event Reporting System (VAERS) standard operating procedure for COVID-19 (as of 29 January 2021). 2021 [cited 2021 May 12]. https:/ / www.cdc.gov/ vaccinesafety/pdf/VAERS-v2-SOP.pdf

6. US Department of Health and Human Services; Vaccine Adverse Event Reporting System. COVID-19 vaccine EUA reporting requirements for providers. https:/ / vaers.hhs.gov/ index.html

Address for correspondence: Mark B. Salzman, Department of Pediatrics, Kaiser Permanente West Los Angeles Medical Center, 6041 Cadillac Ave, Los Angeles, CA 90034, USA; email: mark.b.salzman@kp.org 